No livro Six Easy Pieces do prémio Nobel da Física, Richard P. Feynmam, estão publicadas as suas lições que tiveram lugar em 1961, 1962 no Caltech (California Institute of Technology). O objectivo deste curso era conservar o interesse dos estudantes, que chegavam cheios de entusiasmo. No final o próprio Feynmam reconhece que raramente $o$ ensino é verdadeiramente eficaz, salvo nos casos felizes em que é quase supérfluo. Um assunto que poderia merecer alguma discussão nas páginas deste boletim. Nesse mesmo livro, a primeira peça trata dos átomos em movimento. No caso de suceder um qualquer cataclismo que fizesse perder o conhecimento científico, e em que uma só frase pudesse ser passada à geração sucessiva, interroga-se o autor qual seria o enunciado que conteria a maior informação no menor número de palavras. Feynmam acreditava que seria a hipótese atómica, isto é que todas as coisas são feitas de átomos, pequenas partículas em movimento perpétuo, que se atraem a distâncias curtas, mas se repelem se pressionadas uma contra a outra.

Mas o que mais surpreende no livro de Feynmam (para nós químicos) é o parágrafo seguinte que não resistimos a transcrever... Como faz o Químico para perceber qual a configuração (de uma molécula)? Mistura frascos cheios de coisas, e se vem vermelho quer dizer que há um hidrogénio e dois carbonos estão a ele ligados, se vem azul é tudo diferente. Este é um dos campos de investigação mais fantásticos que tem sido explorado: a Química Orgânica. Para descobrir a configuração dos átomos nestas estruturas enormemente complicadas, o químico olha o que acontece quando mistura duas coisas diferentes. Os físicos nunca acreditaram verdadeiramente nos químicos que descrevem as configuraçôes dos átomos, pensando que na realidade não sabem de que coisa estão falando. Desde há vinte anos que se pode, em certos casos, olhar estas moléculas com métodos físicos e portanto pode-se localizar cada um dos átomos não olhando para a cor de uma mistura, mas medindo onde se encontra. E... oiçam bem, oiçam!, os químicos têm quase sempre razão.

A questão é que o químico está habituado a trabalhar na dimensão do átomo. Uma dimensão privilegiada. É o artífice que junta os peças que fazem as pequenas moléculas, as grandes moléculas, que por sua vez constituem as es- truturas biológicas...e por aí adiante até à vida.

Neste número um dos temas tratados é a Conservação e Restauro do Património Cultural. O entrevistado, Prof. Peixoto Cabral é um químico que desde há muitos anos tem investigado nesta área. A propósito, o Doutor Jaime Oliveira faz o historial do Laboratório de Estudos Nucleares de Sacavém. Outros motivos de boas leituras não faltam. Artigos vários e as secções habituais. Caros leitores, se no vosso entender o boletim merece mesmo ser lido, então leiam-no, critiquem-no, divulgem-no: caso contrário, se têm motivos para discordar, então discordem! A diferença de opinião é um bem da vida.

Um livro é a coisa inanimada que mais se aproxima de um ser vivente. E se a um pacífico animal raramente se recusa uma carícia, então porque não afagar o papel de um bom livro (ou revista!) e beber com os olhos as palavras, página por página; num golo de cada vez como uma bebida forte, ou num sôfrego trago, como a água em dia de muita sede. Na estante sem abrir..ah! isso é certamente pecado!

Boa Primavera.

\title{
NATIRIŔPIn SpR
}

\section{Química - Boletim da Sociedade Portuguesa de Química}

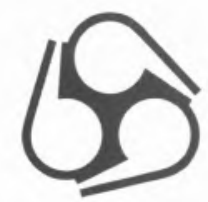

\section{Orientação editorial}

Química, Boletim da Sociedade Portuguesa de Química, versa todos os as- suntos relacionados com a Química, e em particular todos aqueles que dizem respeito à Química em Portugal.

Química publica entrevistas, reportagens, artigos solicitados e propostos, noticiário, recensões de livros e outras publicações e correspondência dos leitores.

É dada preferência a artigos de carácter relativamente geral e escritos de modo a poderem interessar a um vasto leque de leitores.

\section{Normas de Colaboração e Instruções para os Autores}

1. Os artigos devem ser enviados por correio electrónico, para o endereço boletim@dq.fct.unl.pt ou para o endereço do actual Editor da Química, neste triénio, Prof. Fernando Pina, fjp@dq.fct.unl.pt. Alternativamente, podem ser enviados dois exemplares dirigidos ao Editor da Química, Boletim da SPQ, Av. da República, 37-4, 1050-187 Lisboa. 
2. A Redacção acusará a recepção das colaborações propostas e os textos serão apreciados por um ou mais avaliadores. Com base nas apreciações obtidas, a Direcção decidirá da aceitação ou recusa das colaborações propostas; eventualmente, proporá aos autores a reescrita dos textos antes de tomar uma decisão definitiva.

3. Os artigos devem conter um resumo de 50 a 100 palavras com a descrição do respectivo conteúdo. Salvo casos excepcionais, os textos não devem exceder as 3000 palavras ( 5 a 6 páginas da revista, dependendo das figuras); para a Secção de Actividades em laboratório, não devem exceder as 2000 palavras (4 a 5 páginas da revista). As figuras deve- rão ter a qualidade indispensável a uma boa reprodução gráfica.

4. Os artigos devem seguir, tanto quanto possivel, as recomendações da IUPAC quanto à nomenclatura e unidades.

5. Na Bibliografia, a indicação abreviada de artigos deve obedecer à convenção autores-volume-ano-página, por exemplo, E. Martinho, J. C. Oliveira, Química (Boletim da SPQ) 83 (2001) 55. A indicação de livros deverá seguir a convenção autor-título-editor-editora-ano, por exemplo, T. J. Meyer, H. Taube, in Comprehensive Inorganic Chemistry, Vol. 1, G. Wilkinson, R. D. Gillard, J. A. McCleverty (eds.), Pergamon Press, Oxford, 1987, p.331.
6. Em casos especiais, sujeitos à concordância da Direcção da Química, as contribuições poderão ser publicadas em inglês, ou noutra língua estrangeira, devendo então conter um resumo suplementar em português.

7. No caso dos autores desejarem corrigir as provas dos textos aceites para publicação, deverão indicá-lo expressamente quando da submissão do texto.

8. A inobservância de qualquer das normas de colaboração poderá levar à devolução do texto recebido.

9. Os autores de cada artigo receberão gratuitamente entre 10 a 20 separatas do mesmo.

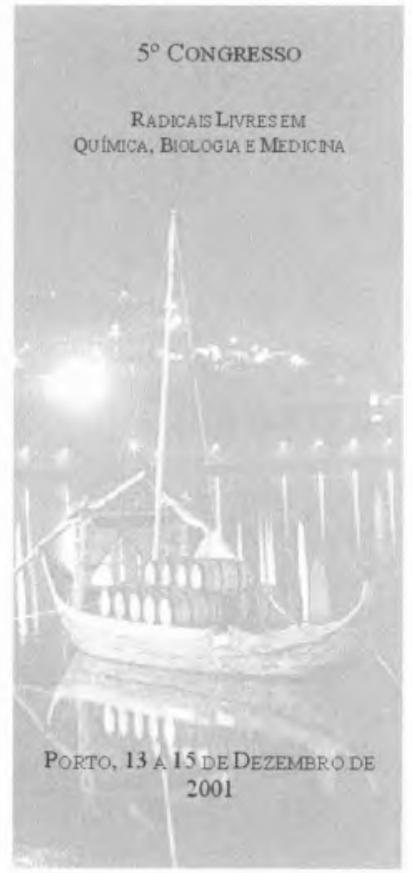

\section{Grupo de Cromatografia}

O 2. ${ }^{\circ}$ Encontro Nacional de Cromatografia decorreu na Torre do Tombo em Lisboa entre 10 e 12 de Dezembro de 2001 , tendo a organização desta conferência sido efectuada uma vez mais com a colaboração do Prof. J. M. F. Nogueira (DQB/FCUL), da Prof. ${ }^{a}$ Ana Costa

\section{$5 .^{\circ}$ Congresso de Radicais Livres em Química, Biologia e Medicina}

Realizou-se de 13 a 15 de Dezembro de 2001, na Faculdade de Farmácia do Porto, o $5^{\circ}$ Congresso de Radicais Livres em Química, Biologia e Medicina. 0 congresso contou com cerca de 90 participantes, entre químicos, bioquímicos, biólogos e médicos. O Programa constou de 5 Conferências Plenárias (Abel Vieira, UNL; Leonor Almeida, FFUC; Moises Canle-Lopez, Univ. Coruña; Juan Bolanos, Univ. Salamanca; Alexandre Quintanilha, ICBAS, Porto), 15 comunicações orais e 33 comunicações em painel,

Como vem sendo hábito desde 1993 , data do primeiro congresso, esta reu- nião proporcionou a todos os que trabaIham na área dos radicais livres e áreas afins, a discussão e intercâmbio de ideias e uma panorâmica dos recentes desenvolvimentos científicos nesta área. É de salientar ainda a elevada participação de estudantes, quer de doutoramento, quer de licenciatura, o que é um saudável indicador da vitalidade desta área científica em Portugal.

Na reunião do grupo de Radicais Livres da SPQ foi eleito como Presidente do grupo para o próximo biénio o Professor Abel Vieira da Universidade Nova de Lisboa. Foi ainda decidido que o próximo Congresso de Radicais Livres se realizará em Coimbra.

IST, 9 de Janeiro 2002

João Paulo Telo
Freitas e do Prof. Marco Gomes da Silva (DQ/FCT/UNL).

0 evento intitulado Fundamentos, Desenvolvimento e Aplicações, teve a participação de mais de cem conferencistas vindos de todo o país e de diversos "stands" de empresas nacionais e espanholas da área da cromatografia.
Estiveram presentes dois distintos cientistas estrangeiros, nomeadamente o Prof. Pat Sandra do Research Institute for Chromatography (Bélgica) e o Prof. Philip Marriott do Royal Melbourne Institute of Technology (Austrália), que proferiram lições plenárias sobre os mais recentes desenvolvimentos em cromatografia. 
Foram efectuadas mais de setenta apresentações cientificas entre liçōes convidadas, comunicações orais e pósteres, onde o denominador comum foi uma vez mais a partilha de experiências entre todos os cientistas nacionais que implementam técnicas cromatográficas.

Houve uma clara adesão de jovens conferencistas, tendo a International Organization for the Promotion of Microcolumn Separations (IOPMS) uma vez mais, atribuido dois prémios às melhores comunicações apresentadas e que se saldou com duas bolsas a estudantes de pós graduação para participação no $25^{\text {th }}$ International Symposium on Capillary Chromatography, a efectuar em Riva del Garda (Itália) em Maio do corrente ano.

A conferência deu igualmente lugar ao curso de Preparação de Amostras para Análise Cromatográfica em colaboração com o Research Institute for Chromatography.

No próximo ano está previsto $\circ 3^{\circ} \mathrm{En}$ contro Nacional de Cromatografia que será atempadamente anunciado, apelando-se por isso mesmo a todos os potenciais cientistas interessados que enriqueçam o evento com a respectiva participação.

\section{Federation of European Chemical Societies}

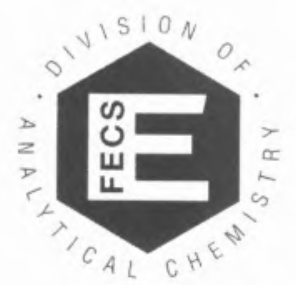

\section{Assembleia Geral da FECS}

Porto, 11-12 de Outubro de 2001

A Assembleia Geral da FECS realizou-se no Departamento de Química da Faculdade de Ciências da Universidade do Porto, tendo sido analisados os assuntos de expediente (boas vindas, justificações de ausência, finalização da ordem de trabalhos), passando-se em seguida à discussão da ordem de trabalhos. Foram feitas apresentações sobre 0 Ensino Superior em Portugal (J. Ferreira Gomes), A Sociedade Portuguesa de Química (J. Ferreira Gomes), O Departamento de Química da FCUP (M. T. Vasconcelos), A Indústria Química em Portugal (S. Feyo de Azevedo) e $A$ Sociedade Portuguesa de Electroquímica (C. Paliteiro).

A discussão incidiu, em grande parte, sobre as orientações a tomar pela FECS no futuro, começando pelo Plano de Acção. Este exige que a FECS tenha um papel mais activo, através da sua participação na AllChemE; num esforço de profisionalização envolvendo mudança de estrutura e objectivos da Comissão Executiva, incluindo a necessidade de arranjar uma sede; organização, de forma ainda mais visivel, de conferências dentro de Divisões e Grupos de Trabalho, e nomeadamente duma Conferência Europeia. Foram criados grupos de trabalho para debater e implementar os vários tópicos. Foi discutido o interesse de criar uma base de dados de Químicos europeus e os problemas legais associados. 0 endereço internet da FECS é http://www.chemsoc.org/ e existem links para as várias sociedades, permitindo a partilha de informação entre sócios da várias sociedades.

Os outros aspectos mais relevantes foram os relatórios apresentados pelos coordenadores das Divisões e Grupos de Trabalho, através dos quais tem lugar a actividade essencial da FECS. Vão-se realizar na Polónia, a 10 e 11 de Outubro de 2002, reuniões da Comissão Executiva e da Assembleia Geral da FECS de 2002.

\section{Relatórios das Divisões e Grupos de Trabalho}

\section{- Analytical Chemistry (D)}

Entre várias conferências, realizou-se em Córdova uma reunião sobre o ensino da Química Analítica (Setembro de 2001). Tem publicado vários trabalhos.

\section{- Food Chemistry (D)}

Têm organizado e vão continuar a organizar conferências. Entre várias, realizou-se a Eurofoodchem (Noruega) onde teve lugar a FECS Lecture. Têm editado várias publicações, embora a nova ver- são de Who's who in Food Chemistry deva vir a ser electrónica.

- Chemical Education (D)

Realizou-se em Aveiro em Setembro de 2001, a EC(RI)CE. A próxima conferênmcia realizar-se-á na Eslovénia. Estão a preparar um texto (.pdf) intitulado Making a presentation in English at a European Conference.

- Chemistry and Environment (D)

Vai-se realizar-se em Atenas, em 2002. a $8^{\text {th }}$ Conference on Chemistry \& the Environment. A 9. ${ }^{a}$ conferência da série terá lugar em Moscovo em 2003.

- Química Organometálica (D)

A XIV th FECHEM Conference on Organometallic Chemistry realizou-se em Gdansk, Polónia, em Setembro de 2001. O novo coordenador da Divisão é o Prof. Kündig (Suiça) que organizará conferência seguinte. A base de dados dos Químicos Organometálicos na Europa está em actualização. Os interessados deverão contactar M. H. Garcia (FCUL).

- Computational Chemistry (WP)

Vai-se realizar-se a $4^{z}$ EUCO-CC3 em Assisi, 1-6 Setembro de 2002. Está concluída a base de dados de Químicos Computacionais, que está em fase de testes e divulgação.

- History of Chemistry (WP)

Está planeada uma conferência para 2003 na Hungria. Foi encontrado um 